\title{
La política exterior japonesa de Koizumi
}

DOI: $10.32870 /$ mycp.v6i18.185

Arturo Santa Cruz*

$\mathrm{E}$ n los albores del siglo XX era común, entre observadores externos, referirse a Japón como el "Reino Unido del Este." Las razones tenían que ver, sin duda, tanto con su carácter insular como con su rápido ascenso económico y político en la escena internacional. Sin embargo, la aventura militarista en que se embarcó el país asiático en los años treinta, que culminó con su desastrosa derrota en 1945, haría que el símil pasara a mejor vida.

A inicios de este nuevo siglo, significativamente, el símil vuelve a ser pertinente - aunque por

otra razón-: el

alineamiento de la política exterior japonesa, bajo el gobierno de Junichiro Koizumi, con la estadounidense. Sobre todo después de los ataques terroristas del 11 de septiembre, la política exterior nipona se asemeja a la que reside en la casa marcada con el 10, Downing Street. Una somera revisión de la política exterior del actual primer ministro japonés Junichiro Koizumi confirma esta aseveración.

Llegado a la presidencia del Partido Liberal Democrático (PLD) y del gobierno de su país de forma no tradicional, es decir, gracias al apoyo no de las facciones dominantes, sino de los comités locales, Koizumi era el retrato vivo de un líder no sólo audaz, sino con amplia legitimidad y margen de acción. Poco después de convertirse en primer ministro, en abril de 2001, el joven

* Investigador del Departamento de Estudios del Pacífico de la Universidad de Guadalajara. primer ministro (a los 59 años un político está todavía tierno para los estándares japoneses) se jactaba de no haber tenido que responder a intereses de las facciones en la conformación de su gabinete. En gran parte por esta autonomía poco usual en la política japonesa, al inicio de su gestión este joven gozaba de niveles de popularidad sin precedentes en el Japón de la posguerra: arriba de $80 \%$, según el promedio de las diferentes encuestas publicadas por los tres principales diarios.

Desde su campaña entre las insatisfechas bases del PLD, en particular, y del electorado, en general, Koizumi había prometido reformas radicales en dos frentes: el económico y el político. En el primer aspecto, el objetivo era relanzar la aletargada economía japonesa y, en el segundo, terminar con el desencanto que producía el corrupto y clientelista sistema político nipón. Ante la serie de fracasos sufridos en estos dos frentes a los pocos meses de su gobierno, los cuales se reflejaron en su 'tasa de aprobación', Koizumi parece haber optado entonces por recurrir al expediente externo para dejar su huella $-\mathrm{y}$ así recuperar su popularidad en casa.

Aunque, para ser justos, hay que anotar que Koizumi empezó a jugar sus cartas en el frente externo desde el primer momento. Nombró en la cartera del Ministerio de Relaciones Exteriores a Makiko Tanaka, quien gozaba de alta popularidad por su estilo directo y sin miramientos, algo no convencional en la política del país del sol naciente. Aunque también, sin duda, debe haber influido en su 
designación el factor sanguíneo: Makiko es hija de Kaukei Tanaka, quien fuera primer ministro en los años setenta. A fines de junio de 2001, Koizumi visitó a su homólogo estadounidense, reunión en la cual refrendaron su pacto de seguridad bilateral como columna vertebral de su relación gubernamental. El primer encuentro entre los dos flamantes mandatarios (Bush asumió la presidencia en enero de 2001) pareció relanzar la relación bilateral después de lo que para efectos prácticos fue el interinato de un año de Yoshiro Mori (a raíz de la repentina convalecencia y subsiguiente deceso del primer ministro Keizo Obuchi).

Poco después sobrevino el conflicto del 11 de septiembre, y tras ese horrendo día los lazos entre Estados Unidos y Japón se hicieron aún más estrechos. Al día siguiente de los ataques, Koizumi hizo público su apoyo a Estados Unidos. Dijo que Japón no escatimaría esfuerzos en asistir y cooperar con lo necesario al país agredido. Exactamente una semana después, el primer ministro japonés definió lo que sería la política básica de su gobierno, en la que la parte medular era el compromiso de involucrarse decididamente en la lucha contra el terrorismo y su deseo de actuar concertadamente con Washington. Esto por supuesto implicaba una desviación significativa de la actitud tradicionalmente pasiva por parte de Japón en la escena internacional desde 1948 —actitud derivada del artículo 9 (“de la paz") de la Constitución de ese año. Aun más: del 24 al 26 de septiembre de 2001, Koizumi visitó la capital estadounidense, viaje en el cual aprovechó, además de expresar las condolencias del emperador, para presentar a su anfitrión la nueva política antiterrorista de su gobierno.

A raíz de los atentados de 2001, la Dieta japonesa aprobó leyes antiterroristas que le permitieron desplazar varios buques abastecedores al Océano Índico para apoyar, indirectamente, la campaña estadounidense contra Afganistán. Las reformas permiten que Japón se involucre en ejercicios militares en un contexto internacional, aunque no se trate de autodefensa - como tradicionalmente se había interpretado la constitución pacifista legada a Japón por la ocupación estadounidense-. La Ley Especial contra el Terrorismo, de septiembre de 2001 (aprobada en octubre), permite a las fuerzas de autodefensa japonesas llevar a cabo apoyo logístico y médico en misiones de rescate y de búsqueda en regiones distantes de Japón. La Ley de Participación en Operaciones de Mantenimiento de la Paz, de diciembre de 2001 , le permite a Japón participar casi completamente en operaciones tradicionales para el mantenimiento de la paz de acuerdo con el capítulo sexto de la Carta de las Naciones Unidas. Así, Japón inició operaciones como el reabastecimiento de embarcaciones en el Océano Índico en diciembre. Posteriormente, Koizumi se convirtió en una especie de cabildero de Washington, enviando cartas a los mandatarios de varios países islámicos en las cuales pedía que se unieran a la lucha contra el terrorismo, enfatizando que no se trataba de una lucha contra el islam.

La rápida reacción de Koizumi después del 11 de septiembre le ganó adeptos en Washington. Desde Foggy Bottom hasta Capitol Hill, pasando por la avenida Pensilvania, se reconocía ampliamente que la respuesta del gobierno japonés había superado las expectativas. El alineamiento con Estados Unidos era apreciado por los electores japoneses: de acuerdo con una encuesta publicada por esas fechas (septiembre 21-22), $70 \%$ de los japoneses estaban de acuerdo con el apoyo ofrecido por su gobierno a Estados Unidos.

Congruente con su postura de involucrarse en la medida de sus posibilidades en la solución de la crítica situación internacional, el gobierno japonés comprometió 120 millones de dólares, aproximadamente $20 \%$ de los recursos requeridos por la ONU para la creación de un fondo para los refugiados de Afganistán y estados circunvecinos. Japón sirvió de anfitrión para una conferencia internacional 
sobre la reconstrucción de Afganistán en enero de 2002.

Sin embargo, la estrategia de Koizumi comenzó a hacer agua en Tokio. La canciller Tanaka rápidamente mostró su incapacidad para hacer frente a los serios problemas de corrupción y rencillas burocráticas que afectaban a su ministerio, involucrándose además en desgastantes conflictos con varios miembros del Parlamento, sobresaliendo el que tuvo con Muneo Suzuki. El problema principal se originó precisamente con una situación que tenía que ver con la guerra en Afganistán a raíz de los atentados del 11 de septiembre. Al estallar un escándalo porque dos organizaciones no gubernamentales fueron vetadas de la conferencia internacional sobre Afganistán, llevada a cabo en Tokio, Tanaka culpó a Suzuki, quien según ella había intervenido indebidamente en el ministerio a su cargo para tal efecto. Suzuki, miembro también del PLD, no sólo negó los cargos, sino que amenazó con impedir la aprobación del presupuesto para 2002. Ante la inminencia de un problema aún mayor, Koizumi optó por sacrificar a Tanaka -cuya versión del incidente confirmaría una investigación parlamentaria posterior-, pero para entonces el paso estaba dado. La sustituyó en el cargo otra mujer: Yoriko Kawaguchi, quien se venía desempeñando como ministra de medio ambiente.

Cuando la administración Bush emprendió su cruzada contra el régimen de Saddam Hussein, arguyendo sus supuestos vínculos con el grupo terrorista $\mathrm{Al}$ Qaeda y su incumplimiento de las resoluciones de la ONU que exigían su desarme, el gobierno de Koizumi se unió a las condenas contra el régimen iraquí, aunque manifestando su preferencia porque el eventual uso de la fuerza se apegara al derecho internacional. Así, el 18 de febrero de 2002 el representante japonés ante la ONU, Koichi Haraguchi, expresó, en una reunión pública del Consejo de Seguridad, que su gobierno consideraba deseable que aquel adoptara una nueva resolución que demostrara claramente la actitud determinada de la comunidad internacional en cuanto a permitir la intervención armada contra Irak, si éste no cumplía inmediatamente con la Resolución 1441, adoptada de manera unánime por ese organismo en noviembre de 2002.

Koizumi incluso cabildeó el nombre de Washington entre algunos miembros del Consejo de Seguridad, un mes antes del inicio de las hostilidades. Una semana antes de que iniciaran los bombardeos en Bagdad, Haraguchi expresó en el mismo foro el apoyo de Japón al proyecto de resolución que para esas fechas proponían conjuntamente España, Estados Unidos y el Reino Unido, el cual era prácticamente un ultimátum al gobierno de Hussein. El representante japonés remarcó que el proyecto propuesto era "verdaderamente un esfuerzo final por mantener la solidaridad internacional," es decir, para que la comunidad internacional sancionara un eventual uso de la fuerza.

Sin embargo, ante la negativa de la inmensa mayoría de los quince miembros del Consejo de Seguridad para avalar el proyecto de resolución propuesto por Estados Unidos y sus dos aliados, éste decidió ignorar la normatividad internacional. Así, Bush emitió un ultimátum de 48 horas a Hussein para dimitir, el que ignoró, lo que provocó que efectivos británicos y estadounidenses iniciaran el ataque el 19 de marzo. Al día siguiente, Koizumi fijó su posición señalando que "Estados Unidos es un aliado irremplazable para Japón y provee una disuasión vital que defiende la paz y seguridad de nuestra nación" y que "en un momento en el que Estados Unidos está a punto de hacer un tremendo sacrificio por la gran causa de la comunidad internacional, es el deber de Japón, como es natural, proveer tanto apoyo como sea posible". Una semana después, Koizumi reiteró su posición, declarando que la comunidad internacional no podía simplemente ignorar el "problema" iraquí, y sancionar el ataque de Estados Unidos y sus aliados. Y lo dijo explícitamente: Japón "apoya las acciones tomadas por Estados Unidos y sus aliados en la coalición". 
Con esta política exterior, centrada en la agenda estadounidense, Koizumi llegó a su segundo aniversario como primer ministro (espacio alentador, pues desde hace más de treinta años no ha habido un primer ministro que llegue a tres años en el cargo). Significativamente, Koizumi celebró la ocasión con el primer ministro británico Tony Blair, en Londres. Los dos jefes de gobierno coincidieron en que es de suma importancia el establecimiento de un sistema que permita la coordinación internacional, a fin de trabajar en la reconstrucción de Irak; aunque dejaron en claro que este esfuerzo deberá llevarse a cabo "en cooperación con Estados Unidos".

Continuando su periplo en el viejo continente, con el fin de limar las asperezas surgidas a raíz de las posiciones divergentes en torno al problema iraquí con algunos países miembros de la Unión Europea, Koizumi coincidió con la postura adoptada por el organismo europeo: que la ONU debe jugar un papel fundamental en la reconstrucción de Irak. El gobierno japonés coincidía con el inglés en torno a este punto, guardando cierta distancia con su aliado común.

Pero si bien la política exterior de Koizumi se ha visto dominada por los efectos de los ataques terroristas del 11 de septiembre, ha habido también otros desarrollos importantes en las relaciones externas del archipiélago. Sobresale, en este sentido, la relación con Corea del Norte. La agenda con este país ha sido doble: la normalización de relaciones diplomáticas y el desarrollo de capacidades militares por parte de Pyongyang.

En lo que respecta a la primera, la cuestión más delicada —desde el punto de vista nipón-es la relacionada con los aproximadamente doce ciudadanos japoneses secuestrados por el régimen norcoreano. Tomando un riesgo calculado, Koizumi decidió realizar una visita a Pyongyang en septiembre de 2002, la primera de un primer ministro japonés a ese país. Uno de los puntos en la agenda era, inevitablemente, el destino de los rehenes japoneses. para sorpresa de todos, en la cumbre bilateral, el gobierno de Kim Jong II admitió la existencia de esta deplorable práctica en su país. Todavía más, se informó al gobierno japonés que ocho de los secuestrados ya habían fallecido (todos por "causas naturales"), y sólo cuatro sobrevivían. Esta información por supuesto causó furor en el archipiélago - y problemas para la popularidad de Koizumi-. Sin embargo, aunque no se habló del regreso de los cuatro rehenes sobrevivientes a su país, seguramente significaría un fuerte impulso a su carrera política si así sucediera durante su mandato.

Por lo que respecta al otro tema sobresaliente de la agenda con Pyongyang, el cual involucra directamente no sólo a Japón sino también a otros países del área y a Estados Unidos, Tokio ha adoptado también una posición similar a la de Washington. En abril de 2000, Corea del Norte y Japón retomaron (después de casi siete años) las pláticas tendentes a la normalización de sus relaciones. Japón forma parte de la Organización para el Desarrollo Energético de la Península Coreana, junto con los gobiernos de Estados Unidos y Corea del Sur. La Organización fue establecida en 1995, como resultado del Marco de Acuerdo al que llegaron Washington y Pyongyang en 1994. Su propósito es financiar y proveer reactores hidráulicos y otras alternativas de energía provisionales, a cambio de que Corea del Norte congele su programa de desarrollo nuclear. El papel de Japón en este organismo es sencillo: ofrecer incentivos para que Corea del Norte abandone sus ambiciones nucleares. Siguiendo una política activa al respecto, durante su visita de septiembre del año pasado, Koizumi abordó el tema con su anfitrión. Aunque dispuesto al diálogo bilateral —al que la administración Bush se negó consistentemente hasta que China actuó como mediador en las postrimerías de la guerra contra Irak-, la posición de Tokio no es tan tolerante en relación con Pyongyang como con Seúl, con su política de "luz de sol" para con su vecino del norte. El gobierno de Koizumi ha dicho claramente que no se debe permitir que 
regímenes peligrosos (entiéndase Corea del Norte) posean armas de destrucción masiva.

La diplomacia dual de Koizumi, sin embargo, pareció funcionar hasta finales del 2002. Después vino el anuncio por parte de Pyongyang en el sentido de que posee capacidad nuclear, lo cual contradice abiertamente la declaración conjunta que comprometía tanto al país peninsular como al insular a respetar los acuerdos internacionales en la materia, y a buscar una solución comprensiva a la cuestión nuclear en la península coreana. A partir de entonces, el gobierno de Koizumi se ha visto fuertemente presionado para soportar el ritmo que marca Washington y adoptar una postura más agresiva con Pyongyang.

Finalmente, el otro frente de la política exterior japonesa que conviene tratar en este recuento es el relacionado con China. Japón es el principal acreedor y socio comercial del "país del centro del mundo." Sin embargo, las agresiones japonesas a China, sobre todo las que precedieron y se dieron durante la segunda guerra mundial, siguen todavía vivas en la memoria del milenario país. El sostenido ascenso económico de este último, desde los años ochenta, ha sido percibido como una amenaza por los japoneses temerosos de que
Pekín tenga ánimos vengativos o simplemente quiera volver a erigirse en el líder hegemónico de Asia. En este sentido, las declaraciones hechas por Koizumi en su primera visita a China, en el sentido de que él no considera el creciente poderío económico de éste como una amenaza para su país, sino como un reto y una oportunidad para incrementar el desarrollo económico nipón, fueron bien recibidas en Pekín. En una reunión privada que el primer ministro japonés tuvo en Cancún, en el marco de la reunión de líderes del APEC, en octubre pasado, con el entonces presidente Jiang Zemin, éste le manifestó su beneplácito por decir públicamente que su país no considera a China como una amenaza.

Así pues, en tanto que la relación bilateral entre los dos principales países del este de Asia parece encontrarse en un momento de tranquilidad, y la del archipiélago nipón con Pyongyang parece haber entrado en un compás de espera por la cuestión nuclear. De lo que no queda duda es que el gobierno de Koizumi ha forjado una relación especial con la administración Bush. Japón parece convertirse otra vez en el Reino Unido del Este -y su primer ministro, como su homólogo británico, tal vez pueda perpetuarse en el cargo por más de 36 meses-. Ty: 